MCKeE, R. K. (1959). J. gen. Microbiol. 20, 686-696

\title{
Factors Affecting the Toxicity of Solanine and Related Alkaloids to Fusarium caeruleum
}

\author{
By R. K. McKEE \\ John Innes Horticultural Institution, Bayfordbury, \\ Hertford, Hertfordshire
}

\begin{abstract}
SUMMARY : Solanine toxicity was assessed by its effect on the viability of spores of Fusarium caeruleum. Factors which were found to influence toxicity included solanine concentration, period of exposure, hydrogen-ion concentration, spore density, the $\mathrm{Na}$ ion/Ca ion ratio and the previous history of the spores. The toxicity of some related compounds was determined, and the toxicity of solanine to some other micro-organisms. The effect of solanine on the growth of $\boldsymbol{F}$. caeruleum in culture was investigated. The nature of the toxic action of solanine on fungus spores and the similarity of spore toxicity to haemolytic activity are discussed. It is concluded that the presence of solanine is unlikely to be an important factor in preventing fungal infection of those tissues in which it is found.
\end{abstract}

The act of wounding potato tubers stimulates the development of a meristem near the wound and the eventual formation of a suberized wound periderm. This periderm provides the exposed cells with mechanical protection against fungi and bacteria, but it has been shown that the adjacent unsuberized tissues also acquire enhanced resistance to infection (McKee, 1954; Müller, 1957).

The changes in chemical composition which take place in the tissues responding to the wound stimulus include a marked increase in their content of solanine (McKee, 1955), a surface-active alkaloid which at low concentrations lyses red blood corpuscles and which is toxic to fungi (Schmidt, 1933). This paper describes observations on the toxicity, in vitro, of solanine and related alkaloids to Fusarium caeruleum (Lib.) Sacc., the cause of dry rot of potatoes; the observations were made during an investigation on the relation between solanine content and tissue resistance (McKee, 1956). The action of solanine on some other micro-organisms is also recorded. Some of the results included here were reported previously in brief (McKee, 1955, 1957).

\section{METHODS}

Alkaloids. Samples of solanine ( $\alpha$-solanine, Kuhn \& Löw, 1954), demissine and tomatine were isolated, respectively, from potato sprouts and from young leaves of Solanum demissum and Lycopersicon pimpinellifolium, by methods based on that described by Wolf \& Duggar (1946). $\alpha$-Chaconine (Kuhn \& Löw, 1954), another trisaccharide of solanidine which occurs in about the same concentration as solanine in potato tissues, was separated by chromatography on buffered cellulose columns (McKee, 1956). Solanidine was prepared by the hydrolysis of solanine (Arnold, 1950). The alkaloids were recrystallized and their purity examined by paper chromatography (McKee, 1957). The relation- 
ships and composition of the Solanum glyco-alkaloids were summarized by Schreiber (1958).

Organisms. An isolate of Fusarium caeruleum (Lib.) Sacc. from a dry-rot lesion in a potato tuber was maintained on potato glucose agar during the investigation. Subcultures were grown from single spores to reduce the risk of selecting fast-growing variants; the appearance of the isolate remained unchanged throughout.

Specimens of Phytophthora infestans, Fusarium avenaceum, F. culmorum, Streptomyces scabies, Erwinia spp. and Pseudomonas spp. were also isolated from diseased potato tubers. Cultures of Bacillus subtilis and Micrococcus luteus were obtained from the culture collection of the Department of Microbiology, Nottingham University School of Agriculture.

Effect of alkaloids on viability of spores. Solutions were prepared containing the alkaloids (as acetates) and buffer and such other salts as are indicated in the description of the experimental work. Phosphate buffers (M/15) were used except where the effect of calcium ion was being investigated, when veronal buffer was used. All experiments were carried out at room temperature $\left(c .18^{\circ}\right)$ and at $\mathrm{pH} 7 \cdot 6$ unless otherwise stated. Spores were placed in small volumes (usually $0.1 \mathrm{ml}$.) of the alkaloid solution and after an interval of 2-3 hr. sample loopfuls of the suspension were streaked on to plates of water agar acidified to $\mathrm{pH} \mathrm{3.5}$ with lactic acid. The $\%$ germination was determined c. $16 \mathrm{hr}$. later, each estimate being based on at least 50 spores. Abbott's correction for natural mortality was applied but this was often unnecessary as germination in control solutions without alkaloid was usually $c .98 \%$. The $\%$ kill figures were changed into probits (Finney, 1952) and were plotted against the dose, transformed logarithmically (dosage) to give a linear relationship between the two.

Effect of alkaloids on rate of growth of Fusarium caeruleum. Growth was estimated by the rate of increase in diameter of colonies on potato extract agar in Petri dishes as basal medium, to which the alkaloids were added.

\section{RESULTS}

\section{Effect of solanine on fungus spores}

Microscopic examination of spores of Fusarium caeruleum which had been exposed to toxic concentrations of solanine showed that the affected cells were shrunken and that their contents were dense and uniform in contrast to the vacuolate appearance of the unaffected cells. The four to five cells in each spore reacted individually, any which were unchanged in appearance retaining the ability to germinate. Spores of $\boldsymbol{F}$. avenaceum and $\boldsymbol{F}$. culmorum behaved similarly. Zoospores of Phytophthora infestans, which consist of naked protoplasts in the presence of solanine came to rest prematurely, suddenly increased in size greatly and then disintegrated, the contents being dispersed-a response analogous to that of the red blood corpuscle. 


\section{Relation between concentration of solanine and its toxicity to spores}

The results of a typical experiment with Fusarium caeruleum spores are shown in Fig. 1 where the probits of \% inhibition of germination are plotted against dose of solanine. The linear relationship was found to hold over wide limits of germination, facilitating the calculation of LD 50 values (probit $=5$ ). These were determined at $\mathrm{pH} \mathbf{7 \cdot 6}$ unless otherwise stated.

Deviations from the line of best fit were small within individual experiments but more variation was found between experiments carried out at different times. Thus repetition, at intervals, of the experiment recorded in Fig. 1 gave LD50 values in the range $\mathbf{2 0 - 3 6} \mathrm{mg}$. solanine/l. with a mean value of $33 \mathrm{mg}$./ $\mathrm{l}$. The mean value of the regression coefficient of probit on dosage was 8.8 , a high value which indicates that small changes in solanine concentration greatly influenced the proportion of spores surviving.

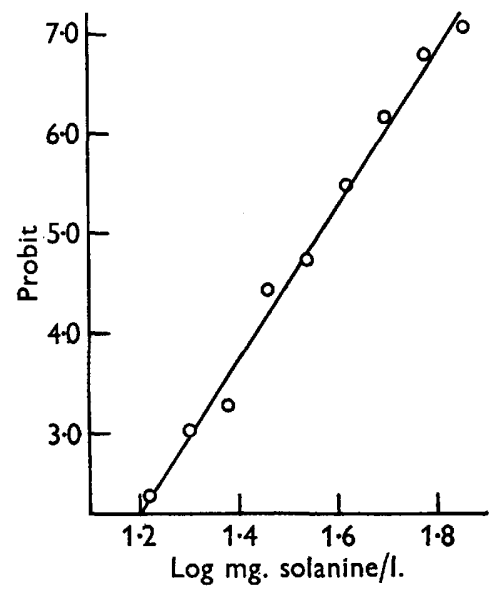

Fig. 1

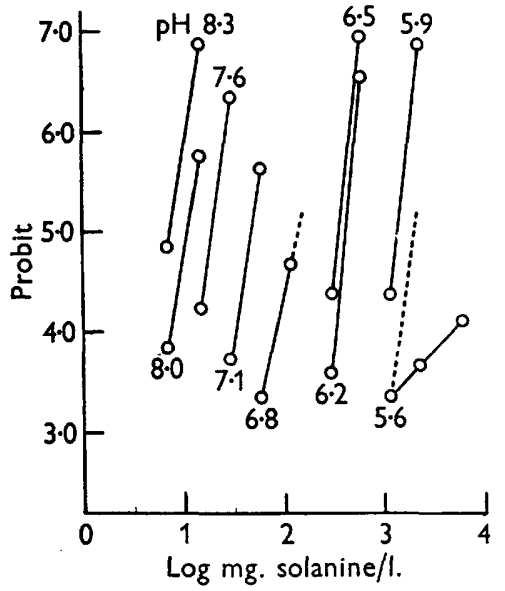

Fig. 2

Fig. 1. Dosage-response curve for inhibition of germination of spores of Fusarium caeruleum by solanine.

Fig. 2. Dosage-response curves at different $\mathrm{pH}$ values for inhibition of germination of spores of Fusarium caeruleum by solanine.

\section{Effect of period of exposure of spores to solanine}

Spore suspensions were mixed with solanine solutions and samples withdrawn immediately and at intervals in order to determine the rate of action of solanine (Table 1). No germination took place in the test solutions as Fusarium caeruleum spores remain dormant when submerged unless very near the surface. The time required for maximal response proved short at the higher solanine concentrations, while even at the lowest concentration used no further decrease in viability was found for periods of exposure greater than $1 \mathrm{hr}$. 
Table 1. Percentage germination of Fusarium caeruleum spores after exposure to solanine solutions

\begin{tabular}{|c|c|c|c|c|}
\hline \multirow{3}{*}{$\begin{array}{l}\text { Period of } \\
\text { exposure } \\
\text { (hr. min.) }\end{array}$} & \multicolumn{4}{|c|}{ Solanine concentration (g./1.) } \\
\hline & 200 & 100 & 50 & 25 \\
\hline & \multicolumn{4}{|c|}{$\%$ germination } \\
\hline 0 & 96 & 98 & 99 & 98 \\
\hline 1 & 60 & 94 & . & • \\
\hline 2 & 1 & 54 & 94 & . \\
\hline 4 & 0 & 2 & 87 & 99 \\
\hline 08 & - & $\mathbf{0}$ & 4 & 96 \\
\hline 015 & . & . & 0 & 53 \\
\hline 030 & - & - & - & 22 \\
\hline 10 & . & - & - & 16 \\
\hline $\begin{array}{ll}4 & 0\end{array}$ & . & . & . & 18 \\
\hline 6 & . & . & . & 19 \\
\hline 240 & - & . & . & 17 \\
\hline
\end{tabular}

Effect of hydrogen-ion concentration

The haemolytic activity of solanine has been shown to be greater in alkaline than in acid solution (Fischer, 1927) and the effect of hydrogen-ion concentration on toxicity to spores was therefore investigated. The LD50 values at different $\mathrm{pH}$ values were determined graphically as indicated in Fig. 2; it will be noted that the slope of the curves was similar except at the lowest $\mathrm{pH}$ value where high concentrations of solanine were required. Here, excess acetic acid in the solanine solution may have lowered the $\mathrm{pH}$ value below the nominal value; extrapolation parallel to the other curves was made from the point for the lowest solanine concentration but this particular LD50 estimate must be regarded as tentative.

The proportion of solanine which is present as undissociated base at any particular hydrogen-ion concentration may be calculated by using the estimate of the dissociation constant of solanidine, $p K_{b}=5 \cdot 38$, given by Bloom \& Briggs (1952). In Fig. 3, the LD50 values determined experimentally are plotted against $\mathrm{pH}$ values. The theoretical curve based on the assumption that only the undissociated molecules are toxic is also shown; this was adjusted to coincide with the experimental curve at $\mathrm{pH} 7 \cdot 0$. The good agreement between the two suggests that the undissociated base was in fact responsible for most of the toxicity.

\section{Effect of concentration of spore suspension}

The relationship between concentration of spore suspension and solanine toxicity was investigated at $\mathrm{pH}$ values 6.5 and 8.0. Spores of Fusarium caeruleum were washed with the appropriate buffer solution, separated by centrifugation and made up into strong suspensions from which a series of dilutions in buffer were prepared. Samples from these were mixed with buffer solutions, each containing solanine at a concentration sufficient to allow about 4. \% germination at the lowest concentration of spores. Samples were plated out after exposure for $4 \mathrm{hr}$. and \% germination observed (Fig. 4). The highest 
concentration of spores in the test solution was $c .3 \%$ by volume. At the higher solanine concentration, increases in spore concentration up to about 40 times the minimum had little effect on \% spores affected, though this decreased when the concentration of spores was further increased. At the lower solanine concentration, any increase in spore concentration decreased the kill.

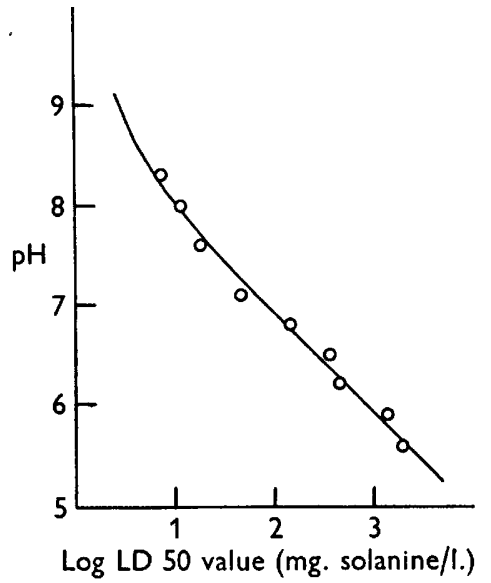

Fig. 3

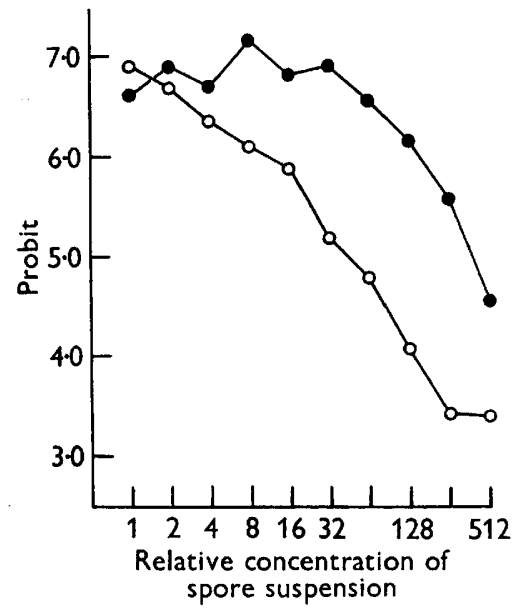

Fig. 4

Fig. 3. Relationship between LD50 value and $\mathrm{pH}$ value for inhibition of germination of spores of Fusarium caeruleum by solanine. $O$, experimental values; $\stackrel{-}{\longrightarrow}$, theoretical curve.

Fig. 4. Relationship between response to solanine and concentration of spore suspension (F. caeruleum). ○— $\bigcirc, 27 \mathrm{mg}$. solanine/l., pH 8.0; pH 6.5.

\section{Effect of electrolytes}

The activity of many haemolytic substances appears to be influenced by changes in the concentration and nature of the accompanying electrolytes in the test solution (Ponder, 1948) but such changes can themselves cause haemolysis of the red blood corpuscles. The spores of Fusarium caeruleum proved to be unaffected by a wide range of salt contents so that it was possible to determine the effect of electrolytes on the toxicity of solanine without having to make allowance for a toxic effect of the salts themselves.

Solanine toxicity was found to increase with increasing concentrations of sodium or potassium ions. Where the concentration of such ions was low, spores were unaffected by exposure even to high solanine concentrations. Addition of glucose up to a concentration of $10 \%(w / v)$ did not restore solanine toxicity in such solutions, indicating that their osmotic pressure was not a decisive factor. Preliminary experiments showed that sodium and potassium ions had equivalent effects, so more detailed experiments were carried out with sodium alone (Fig. 5).

Solanine toxicity was decreased in the presence of calcium ions, being dependent on the sodium ion/calcium ion ratio (Fig. 6). An increase in calcium- 
ion concentration compensated a much larger increase in sodium-ion concentration, the value of the ratio being about 1:350, though this varied with changes in actual ionic concentration (Fig. 7). The effect of calcium was nullified when sufficient EDTA (disodium salt of ethylenediaminetetra-acetic acid) was added to chelate the calcium ions present, these concentrations of EDTA alone being non-toxic to the spores. Solanine toxicity was not diminished in the presence of magnesium ions.

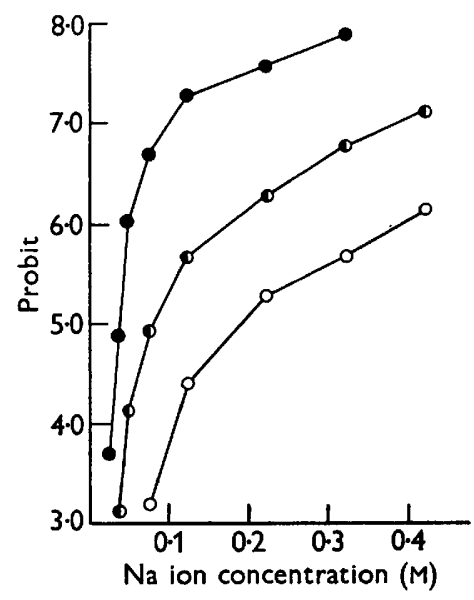

Fig. 5

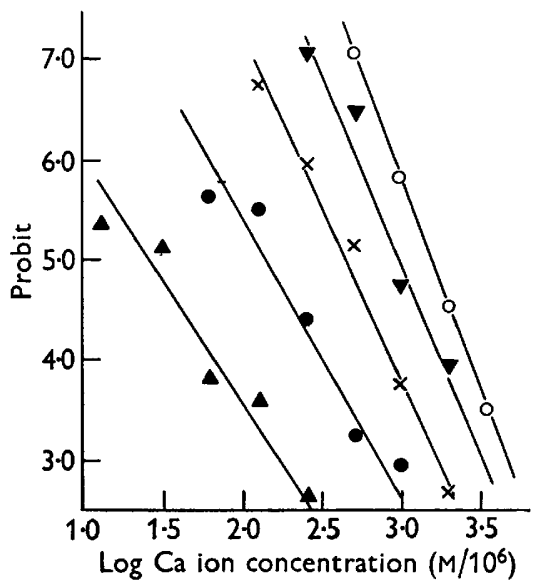

Fig. 6

Fig. 5. Relationship between response of spores of Fusarium caeruleum to solanine and concentration of sodium ions. $\bigcirc-0,25 \mathrm{mg}$. solanine/l.; $\mathrm{O}-\mathrm{O}, 42 \mathrm{mg}$. solanine/ $1 . ; \bigcirc 62 \mathrm{mg}$. solanine/l.

Fig. 6. Relationship between response of spores of Fusarium caeruleum to solanine and concentration of calcium ions. $\triangle-\Delta, 0.07 \mathrm{M}-\mathrm{Na}^{+} ;-0,0.12 \mathrm{M}-\mathrm{Na}^{+} ; \times-\times$, $0.22 \mathrm{M}-\mathrm{Na}^{+} ; \nabla-\nabla, 0.32 \mathrm{M}-\mathrm{Na}^{+} ; \mathrm{O} \longrightarrow \mathrm{O}, 0.42 \mathrm{M}-\mathrm{Na}^{+} .62 \mathrm{mg}$. solanine/l.

\section{Sensitivity of spores of Fusarium caeruleum}

The LD values of different batches of spores from a stable isolate of Fusarium caeruleum, assessed under identical conditions, were found to be influenced by characteristics of the spores themselves. Macrospores from mature cultures were more tolerant of solanine than those from young cultures. A further increase in tolerance occurred in old cultures where individual cells of some of the macrospores developed into thick-walled chlamydospores. These proved capable of germination in solutions containing solanine in concentrations sufficient to kill all the accompanying macrospore cells-possibly owing to absorption of solanine by the macrospores before the germ-tube had emerged from the chlamydospore.

The sensitivity of spores from cultures grown on potato glucose agar to which $0.4 \%$ (w/v) calcium chloride had been added was identical with that of spores produced on potato glucose agar alone. The sensitivity was, however, decreased when $500 \mathrm{mg}$. solanine/l. was included in the medium as well as the calcium chloride. In a typical experiment, an LD50 value of $68 \pm 4 \mathrm{mg}$. 
solanine/l. was obtained for spores from a treated culture, compared with $38 \pm 3 \mathrm{mg}$./ 1 . for spores from the control culture containing calcium chloride but no solanine. The values of the regression coefficient of probit on dosage were always lower for the treated spores than for the controls, but the differences were not significant owing to high values of $\chi^{2}$ in the probit analysis. The growth rate of $F$. caeruleum was unaffected by solanine in the presence of calcium so it appears unlikely that the decrease in sensitivity can be attributed to the selection of more resistant lines.

\section{Toxicity of solanine to other micro-organisms}

Macrospores of Fusarium avenaceum and $\boldsymbol{F}$. culmorum, and sporangia of Phytophthora infestans were found to have a sensitivity to solanine similar to that of $F$. caeruleum spores, namely, an LD50 value of c. $30 \mathrm{mg}$. solanine/l. Zoospores of $\boldsymbol{P}$. infestans proved very sensitive, all in a sample being killed by $5 \mathrm{mg}$. solanine/l. so that the LD50 value would be even less than this.

The viability of spores of Streptomyces scabies was not affected by several hours of exposure to $2000 \mathrm{mg}$. solanine/l. Bacteria from young cultures of Bacillus subtilis, Micrococcus luteus, Erwinia spp. and Pseudomonas spp. were also unaffected by this concentration of solanine.

\section{Toxicity of compounds related to solanine}

The LD50 value of $\alpha$-chaconine was $11 \mathrm{mg}$./l., compared to $20 \mathrm{mg}$. solanine/l. for the same sample of spores of Fusarium caeruleum. Solanidine (LD50 value $100 \mathrm{mg}$./1.) proved less toxic than solanine; this may have been partly due to its low solubility. The undissociated base of solanidine is much less soluble than that of solanine though the solubility of the latter is only $20 \mathrm{mg}$./l. (Rooke, Bushill, Lampitt \& Jackson, 1943). The proportion of $F$. caeruleum spores affected by solanidine after $24 \mathrm{hr}$. was not greater than that after exposure for $4 \mathrm{hr}$.

Table 2. LD 50 values (mg./l.) for solanine, demissine, tomatine and digitonin for Fusarium caeruleum spores

\begin{tabular}{|c|c|c|c|c|}
\hline \multirow{2}{*}{$\underset{\text { value }}{\mathrm{pH}}$} & \multicolumn{4}{|c|}{ LD50 (mg./l.) } \\
\hline & Solanine & Demissine & Tomatine & Digitonin \\
\hline $5 \cdot 0$ & $\bullet$ & - & • & 27 \\
\hline $5 \cdot 6$ & 2000 & • & 460 & • \\
\hline $5 \cdot 9$ & 1100 & 260 & 220 & - \\
\hline $6 \cdot 5$ & 260 & 72 & 64 & 18 \\
\hline $7 \cdot 0$ & 85 & 22 & 32 & • \\
\hline $7 \cdot 6$ & 20 & 11 & 18 & - \\
\hline 8.0 & 11 & . & . & 14 \\
\hline - 3 & 8 & 8 & 7 & $\bullet$ \\
\hline
\end{tabular}

Demissine and tomatine were more toxic for Fusarium caeruleum spores than was solanine, especially in the more acid solutions (Table 2). The free base of both compounds tended to separate as a gel more readily than that of solanine, indicating a low solubility. In contrast to solanidine, the proportion 
of spores affected increased when the period of exposure was extended to more than $4 \mathrm{hr}$.

The steroid saponins are closely related in structure to the Solanum glycoalkaloids but differ from them in being neutral compounds. The $\mathbf{N}$ atom which in the alkaloids forms a secondary or tertiary amine is replaced in the saponins by an $\mathrm{O}$ atom in a heterocyclic ring. The LD50 value of the steroid saponin digitonin showed only minor change over a wide range of $\mathrm{pH}$ values (Table 2). The triterpenoid saponins possess haemolytic activity though less so than the

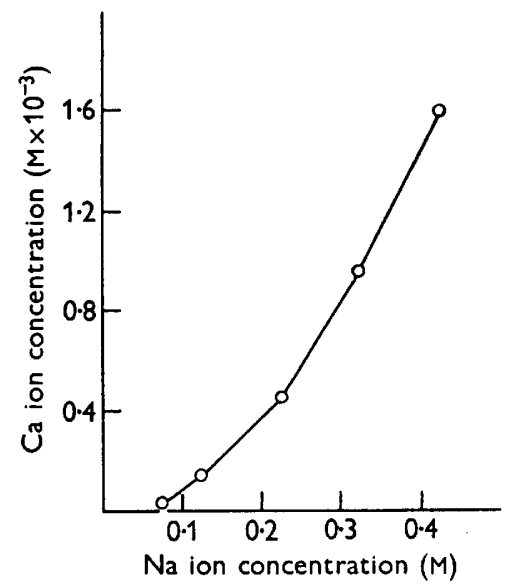

Fig. 7

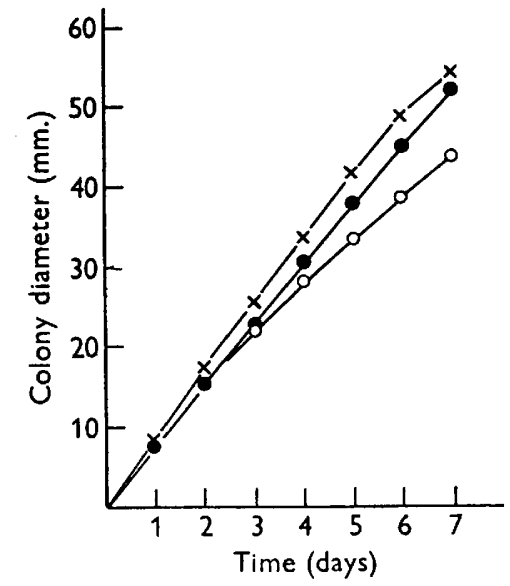

Fig. 8

Fig. 7. Relationship between concentrations of sodium ion and of calcium ion giving $\mathbf{5 0} \%$ inhibition of germination of spores of Fusarium caeruleum by $62 \mathrm{mg}$. solanine/l.

Fig. 8. Effect of solanine on growth of Fusarium caeruleum on potato extract agar. potato extract alone; $O-O$, potato extract $+500 \mathrm{mg}$. solanine/l.; $x-x$, potato extract $+500 \mathrm{mg}$. solanine $/ 1 .+1 \%(\mathrm{w} / \mathrm{v}) \mathrm{CaCl}_{2}$.

steroid saponins (Pethica \& Schulman, 1953). 'Saponin, pure white' at $1000 \mathrm{mg}$./l. showed no toxicity to spores of $F$. caeruleum at $\mathrm{pH} 4.5$ or at pH $7 \cdot 6$.

\section{Effect of solanine on the growth of Fusarium caeruleum in culture}

Potato extract was used as the basal medium in experiments on the effect of solanine on the growth of $F$. caeruleum in culture since the changes in $\mathbf{p H}$ value during growth in this medium were similar to those in tuber tissues attacked by the fungus. The initial growth rate on potato extract containing $500 \mathrm{mg}$. solanine/l. was identical with that on the extract alone (Fig. 8), but after 3 days the growth rate in the presence of solanine decreased though the fungus continued to grow until the experiment was concluded. Addition of calcium chloride to the medium prevented the depressive action of solanine and also increased the steady growth rate over that of the control. In similar experiments it was shown that the retarding action of solanine was prevented when $2 \%(\mathrm{w} / \mathrm{v})$ glucose was added to the potato-extract medium. 
The changes in $\mathrm{pH}$ value (Table 3 ) which took place during growth of Fusarium caeruleum on potato-extract liquid medium offer an explanation of the delayed effect of solanine on growth rate and of the effect of added glucose. In the medium alone, the $\mathrm{pH}$ value increased until, after several days, a value was reached where solanine was highly toxic; with added glucose the $\mathrm{pH}$ value

Table 3. Change in $\mathrm{pH}$ value of culture media during growth of Fusarium caeruleum

\begin{tabular}{|c|}
\hline $\begin{array}{l}\text { Period of } \\
\text { growth } \\
\text { (days) }\end{array}$ \\
\hline 0 \\
\hline 1 \\
\hline 2 \\
\hline $\mathbf{3}$ \\
\hline 4 \\
\hline 5 \\
\hline 8 \\
\hline 14 \\
\hline
\end{tabular}

$\begin{array}{cc}\begin{array}{c}\text { Potato-extract } \\ \text { medium }\end{array} & \begin{array}{c}\text { Potato-extract } \\ \text { medium }+2 \% \\ (\text { w/v) glucose }\end{array} \\ 5 \cdot 2 & 5 \cdot 2 \\ 5 \cdot 8 & 5 \cdot 4 \\ 5 \cdot 8 & 5 \cdot 3 \\ 6 \cdot 7 & 5 \cdot 0 \\ 7 \cdot 4 & 4 \cdot 5 \\ 8 \cdot 2 & 3 \cdot 8 \\ 8 \cdot 6 & 7 \cdot 6 \\ 8 \cdot 7 & 7 \cdot 6\end{array}$

Table 4. Hydrolysis of solanine during growth of Fusarium caeruleum in potato-extract medium containing initially solanine $(500 \mathrm{mg} . / \mathrm{l}$.) and calcium chloride $(1 \%, w / v)$

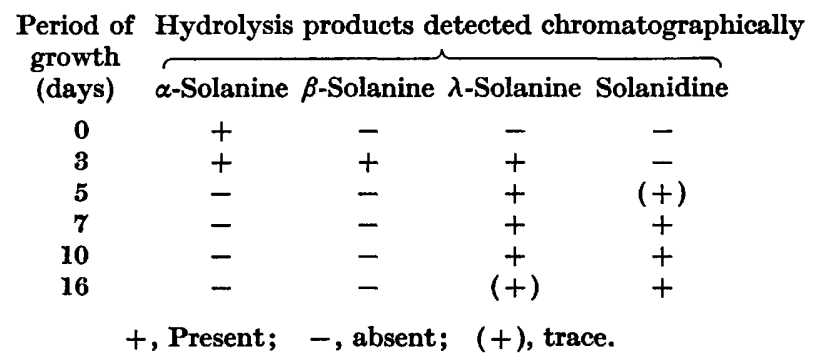

decreased for several days and then began to increase. The fact that growth continued, though at a lower rate, in the presence of solanine even when the medium had become alkaline might be taken to indicate that the growing mycelium was less sensitive (or had become less sensitive) to solanine than the macrospores. However, solanine was found to be hydrolysed (Table 4) by the fungus to the less toxic solanidine via the intermediate glycosides, whose toxicity was not assessed as samples of them were not isolated. It is therefore difficult to define the conditions to which the advancing mycelium was, in fact, exposed.

\section{DISCUSSION}

The rapid disintegration of the naked protoplasts of the zoospores of Phytophthora infestans when exposed to toxic concentrations of solanine suggests that the alkaloid affects the surface membrane of the spore, and that the toxic action of solanine on fungal cells is thus similar in nature to its haemolytic activity. The haemolytic activity of some surface active agents has been 
shown to be greater than would be expected from their surface activity alone, and to be related to their ability to penetrate and cause collapse of cholesterol monolayers which may be considered as experimental analogues of the cholesterol-phospholipid-lipoprotein complex of the cell envelope (Schulman, Pethica, Few \& Salton, 1955). The molecule of the aglycone solanidine can be derived structurally from that of cholesterol by the addition of a nitrogen atom; the toxicity of the glycoside solanine and related compounds may well be connected with this relationship. The lack of toxicity shown by the surfaceactive triterpenoid saponin to Fusarium caeruleum is of interest in this respect as is the absence of toxicity of solanine for bacteria.

The relationship between solanine toxicity and hydrogen-ion concentration indicates that toxicity is restricted to molecules of undissociated base whose concentration must exceed a certain value before the surface membrane is affected. Equilibrium is maintained by association of ionized molecules in the solution when the undissociated base is removed by combination with spores. Thus the concentration of the spore suspension had more effect on solanine toxicity at $\mathrm{pH} \mathrm{8.0} \mathrm{than} \mathrm{at} \mathrm{pH} 6.5$ where most of the solanine was present in the ionized state. The dependence of solanine toxicity, or perhaps of spore sensitivity, on the relative concentrations of sodium or potassium and calcium ions is striking, and it would be of interest to see whether the haemolytic activity of solanine is similarly affected.

The part played by the solanine in potato tissues in protecting them against fungal infection and subsequent invasion is difficult to assess since solanine toxicity in vitro is influenced so much by factors, such as $\mathrm{pH}$ value, which may vary in the tissues concerned. However, it would seem unlikely that the solanine content plays a decisive part in controlling infection, at least by Fusarium caeruleum, in view of the ability of this fungus to grow in the presence of solanine in media where conditions appear similar to those found in dry-rot lesions in tuber tissues. This conclusion is supported, though negatively, by the fact that no correlation was demonstrated between susceptibility of tubers to dry-rot infection and their ability to accumulate solanine near wounds when these were measured at intervals during the storage season (McKee, 1956).

I would like to thank Professor C. G. C. Chesters and Dr A. R. Wilson for their interest and encouragement in this work which was carried out at the Agricultural Research Council Potato Storage Investigation, c/o University of Nottingham School of Agriculture, Sutton Bonington, Loughborough, Leicestershire.

\section{REFERENCES}

ArNold, W. (1950). Eine verbesserte Methode zur Gewinnung und quantitativen Bestimmung des Solanins, des Glycoalkaloids der Kartoffelpflanze. Pharmazie, $5,490$.

Bloom, H. \& Briggs, L. F. (1952). Solanum alkaloids. Part. IX. The relation between constitution and basicity in solasodine, its derivatives and solanidine. J. chem. Soc. 3591.

Finney, D. J. (1952). Probit Analysis. Cambridge University Press. 
Fischer, R. (1927). Der Einfluss der Wasserstoffionenkonzentration auf die Solanin-Hämolyse. Biochem. Z. 209, 319.

Kuhn, R. \& Löw, I. (1954). Die Konstitution des Solanins. Angew. Chem. 66, 639.

McKeE, R. K. (1954). Dry-rot disease of the potato. VIII. A study of the pathogenicity of Fusarium caeruleum (Lib.) Sacc. and Fusarium avenaceum (Fr.) Sacc. Ann. appl. Biol. 41, 417.

McKeE, R. K. (1955). Host-parasite relationships in the dry-rot disease of potatoes. Ann. appl. Biol. 43, 147.

MCKEE, R. K. (1956). Studies on the toxicity of solanine and related compounds to micro-organisms and on the influence of solanine content on the resistance of potato tuber tissues to fungal infection. University of Nottingham, Ph.D. Thesis.

MCKEE, R. K. (1957). Solanine and related alkaloids. Nature, Lond. 179, 313.

Müller, K. O. (1957). Wound healing of the potato tuber in relation to infection by Phytophthora infestans (Mont.) de Bary. Aust. J. Biol. Sci. 10, 189.

Pethica, B. A. \& Schulman, J. H. (1953). The physical chemistry of surface active agents. Biochem. J. 53, 177.

Ponder, E. (1948). Hemolysis and Related Phenomena. London: J. and A. Churchill.

Rooke, H. S., Bushill, L. H., Lampitr, L. H. \& Jackson, E. M. (1943). Solanine, glycoside of the potato. I. Its isolation and determination. J. Soc. chem. Ind., Lond. 62, 20.

SснміDт, M. (1933). Zur Entwicklungsphysiologie von Cladosporium fulvum und über die Widerstandfähigkeit von Solanum racemigerum gegen diesen Parasiten. Planta, 20, 407.

Schreiber, K. (1958). Über einige Inhaltsstoffe der Solanaceen und ihre Bedeutung für die Kartoffelkäferresistenz. Ent. exp. \& appl. 1, 28.

Schulman, J. H., Pethica, B. A., Few, A. V. \& Salton, M. R. J. (1955). The physical chemistry of haemolysis and bacteriolysis by surface active agents and antibiotics. Progr. Biophys. 5, 41.

Wolf, M. J. \& Duggar, B. M. (1946). Estimation and physiological role of solanine in the potato. J. Agric. Res. 73, 1.

(Received 8 December 1958) 